Ciência e Natura, Santa Maria, v. 37 n. 3 set-dez. 2015, p. 821-832

Revista do Centro de Ciências Naturais e Exatas - UFSM

ISSN impressa: 0100-8307 ISSN on-line: 2179-46017643

\title{
ciênciaenatura
}

\section{Atividades baseadas na Aprendizagem Significativa (AS): avanços na Educação de Jovens e Adultos a partir da Interdisciplinaridade como atitude do professor}

\author{
Activities based in Meaningful Learning ( $M L$ ): advances in Adult Education from the \\ Interdisciplinary as a teacher's attitude
}

André Taschetto Gomes ${ }^{1}$ Isabel Krey Garcia² e Lisiane Barcellos Calheiro ${ }^{3}$
${ }^{1}$ Mestre em Educação em Ciências, Doutorado em andamento pelo PPG Educação em Ciências (UFSM), Docente da rede básica de Ensino (SEDUC-RS), Santa Maria-RS, Brasil.atg.andre@gmail.com
${ }^{2}$ Professora Doutora, Departamento de Física, UFSM, Santa Maria-RS, Brasil.
${ }^{3}$ Mestre em Educação em Ciências, Doutorado em andamento pelo PPG Educação em Ciências (UFRGS),
Docente da rede básica de Ensino (SEDUC-RS), Santa Maria-RS, Brasil.

\begin{abstract}
Resumo
Com o intuito de avaliar uma proposta de ensino a partir da atitude interdisciplinar do professor e dos pressupostos da aprendizagem significativa, o presente estudo, resultado de uma dissertação de mestrado em Educação em Ciências, buscou investigar, inicialmente, as concepções iniciais dos alunos em relação à Energia. A partir do mapeamento dos seus interesses relacionados ao tema, bem como a determinação do seu perfil sócio-educacional, foi desenvolvida uma sequência didática com duas turmas de educação de jovens e adultos (EJA), em uma escola estadual pública, de Santa Maria, RS. A partir da análise dos resultados, constatou-se um avanço significativo na estrutura cognitiva dos pesquisados, sendo que cerca de 91\% evoluíram conceitualmente, diminuindo a fragmentação da compreensão de seu significado, o qual era primeiramente atribuído a Movimento, Vida, Materialismo e Funcionalismo, e, após, a compreensões mais adequadas cientificamente, Transformação, Fluxo e Origem. A interdisciplinaridade como atitude do docente, apresentando o tema de forma ampla e global, se mostrou essencial para uma progressiva diferenciação e reconciliação dos conceitos relacionados à energia. A EJA apresenta-se como campo bastante promissor para estudos na área de Educação em Ciências que consideram a interdisciplinaridade e a AS em seus referenciais teóricos.
\end{abstract}

Palavras-chave: EJA, Temática, Material Potencialmente significativo, Concepções iniciais de Energia, Interdisciplinaridade.

\begin{abstract}
In order to evaluate a teaching proposal from the interdisciplinary teacher attitude and assumptions of meaningful learning, this study, the result of a master's thesis in Science Education, sought to investigate, initially, the initial conceptions of studants with respect to Energy. From the mapping of their interests related to the topic, as well as determining the socio-educational profile, was developed a teaching sequence with two groups of young and adult education (EJA), in a public state school, in Santa Maria, RS. From the analysis of the results, it was found a significant advance in cognitive structure of respondents, and about 91\% developed conceptually, reducing the fragmentation of understanding of its meaning, which was primarily attributed to Motion, Life, Materialism and Functionalism, and, after, the most appropriate understandings scientifically, Transformation, Flow and Source. The interdisciplinarity as an attitude of teaching, presenting the theme of broad and comprehensive manner, was essential to a progressive differentiation and reconciliation of the concepts related to energy. The EJA is presented as a promising field for studies in the Science Education to consider interdisciplinarity and the AS in their theoretical frameworks.
\end{abstract}

Keywords: Adult Education,Thematic, Potentially meaningful material, Initial conceptions of Energy, Interdisciplinarity.

\section{Introdução}


E

nergia é um dos vocábulos que amplamente utilizamos em nosso cotidiano. Porém, nem sempre sua compreensão está associada ao que a Ciência considera como mais adequado. Nos múltiplos pontos que aparece, seja nas abordagens nutricional, atômica, elétrica, cinética, eletroquímica, natural, radioativa, entre outras, acabam tornando-o complexo e de difícil entendimento (RUSSO, 2007). Em um delineamento, conforme o significado atribuído pelos conhecimentos mais atuais, Energia é a possibilidade potencial de gerar transformações no meio material (BOSQUILA et al., 2012; BARBOSA e BORGES, 2006; WIRZBICKI, 2010). As tecnologias, nesse sentido, são meios criados para transformar os recursos da natureza em energia que pode ser utilizada pelo homem.

Diferentes conceituações são atribuídas, pelas ciências, ao seu significado. Contudo, pode ser, de forma mais clara, observado em alguns eventos: nos movimentos, no calor de uma vela, na luz emanada do sol, nas ondas de som, na eletricidade que percorre linhas de transmissão, dentre outros episódios onde a energia sofre modificações quanto a sua forma (GASPAR, 2009). No currículo escolar, este conceito é um dos mais complexos de ser entendido devido a sua abstração, o que causa muitas vezes compreensões inadequadas, o confundindo com força, movimento e potência (BARBOSA \& BORGES, 2006).

A pouca de contextualização considerando uma visão ampla no seu ensino e a perspectiva muito disciplinar, em sua abordagem nas instituições escolares, são, provavelmente, de acordo com a literatura, as principais circunstâncias para entendimentos pouco adequados e significativos. $\mathrm{O}$ amplo número de concepções inadequadas sobre sua definição é decorrente de sua extrema abstração, o que torna árdua sua compreensão pelos estudantes (JACQUES et al.,2009).

Para entendermos os fenômenos naturais, sejam de origem física, química, biológica e tecnológica, este conceito é essencial e primordial quando se almeja um ensino que propicie uma educação científica crítica (BESSON \& AMBROSIS, 2014). Devido à amplitude de sua abordagem conceitual, podendo ser enfocado em
Química, Geografia, História, Educação Física, Sociologia, entre outras, suas aplicações se tornam geralmente específicas, tornando seu entendimento global e menos fragmentado, mais difícil.

Em conseqüência de suas múltiplas aplicações, envolvido em diversas áreas do saber, ele pode ser compreendido, infelizmente, de forma errônea ou apenas denotando alguns de seus aspectos (WIRZBICKI, 2010). A perspectiva pouco interdisciplinar e ampla que geralmente os professores abordam este conceito em aula, atrelado a assuntos como fotossíntese, reações química, trabalho, respiração, trocas energéticas, transformações, etc. (MACHADO et al., 2011), pode ser decorrente do entendimento fragmentado por disciplinas, já que a Energia abordada em Química muitas vezes não apresenta muitas relações com o que é visto em Física pelos alunos, por exemplo.

A contextualização nas intervenções deve denotar uma abordagem global para o conceito. Sendo que, de forma gradual, se devem abordar os pontos mais específicos relacionados à Energia com a realidade onde as atividades estão sendo propostas, bem como os interesses dos estudantes. Essa grave falta de relações não estabelecidas, quando se trata de abordar seu significado geral, pode ser observada também nos livros didáticos. Estes o tornam mais obscuro e de difícil compreensão devido ao caráter extremamente fragmentado e disciplinar que é dado em suas abordagens.

Neste sentido, a atitude interdisciplinar (Figura 1) pode ser uma alternativa do professor ao abordar este assunto, complementando e fazendo as relações entre a energia vista em Biologia, Física e Química (ARAÚJO \& NONENMACHER, 2009). Os livros didáticos, ao conceituá-lo em função do enunciado genérico "A energia não pode ser criada, nem destruída, mas apenas transformada", se referem aos aspectos de fenômenos naturais; quando o tratam apenas como "é a capacidade de realizar trabalho", a definição se torna muito pontual ao campo da física. Vistas isoladamente, estas duas concepções causam o surgimento da idéia errônea de que de que energia comporta-se como "substância", resultante da visão eclética e fragmentada que é abordada (COELHO, 2014).

diversas disciplinas como Biologia, Física, 


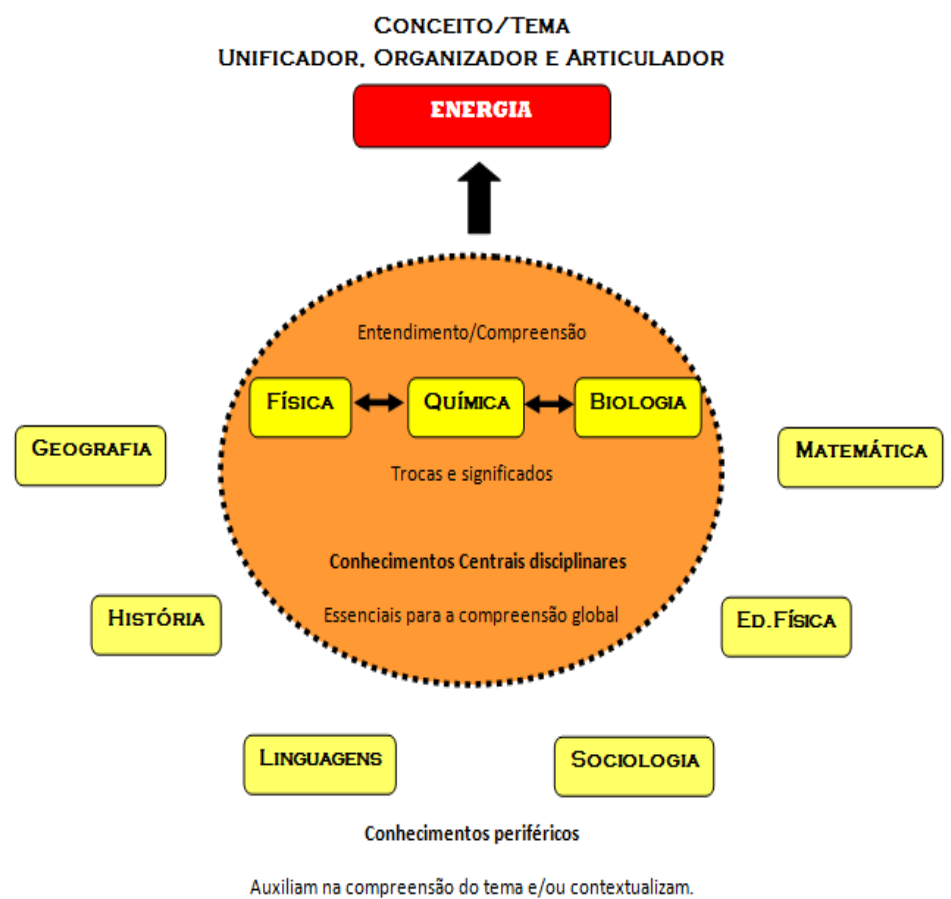

Figura 1. Interdisciplinaridade relacionada à Energia. (Fonte: TASCHETTO, 2014).

\section{A abordagem disciplinar e a extensa lista de idéias iniciais de Energia}

A primeira etapa, em qualquer intervenção didática que priorize a avaliação da aprendizagem pelos estudantes, ao final do processo, é o mapeamento das concepções prévias da estrutura cognitiva. Em virtude da abordagem extremamente fragmentária de seu significado, deve-se ter claro o que os alunos compreendem sobre este conceito.

A ampla lista de significados atribuídos à Energia, que será apresentada a seguir, é possivelmente resultante da maneira específica e inadequada que o ensino disciplinar o trata nas aulas de ciências. Para que ocorra uma aprendizagem significativa, segundo a teoria de Ausubel (1980), estes conceitos atribuídos inicialmente podem servir de base para os conhecimentos novos, ocorrendo múltiplas interferências e relações entre estes saberes.

Contudo, algumas concepções podem se tornar obstáculos para a aprendizagem de novos conceitos. Nesse sentido, o professor deve partir da negociação de significados, promovendo uma diferenciação progressiva do significado de Energia, o tomando geral como princípio e abordando, na sequência, relações mais pontuais e específicas. Estas novas informações se transformam em conhecimentos relevantes quando são incorporadas à cultura dos alunos. Abordar os conhecimentos das ciências nesta perspectiva pressupõe fazer as ligações necessárias entre as disciplinas, relacionando com aspectos históricos, filosóficos e sociais dos conteúdos. Esta visão proporciona uma educação científica mais efetiva, tornando os alunos participantes ativos da aprendizagem, denotando, também, uma postura crítica, reflexiva e engajada de transformação pessoal, assim como uma compreensão mais adequada dos assuntos da ciência no seu dia a dia (ZANETIC, 2005).

A mediação da aprendizagem deve interligar os assuntos, explorando e facilitando a compreensão do mundo e suas interações. Tem um caráter fundamental, para que ocorram aprendizagens significativas, um ensino contextualizado de Biologia, Física e Química de modo inter-relacionado, refletindo sobre o contexto social e cultural (MORAES, 2008). Ter como pressuposto uma atitude interdisciplinar, significa um diálogo para melhor compreender um conceito em diversas situações (BOFF et al., 2008).

Assim, as diversas disciplinas escolares, deveriam facilitar a compreensão dos fenômenos 
presentes no cotidiano dos alunos (BUSQUETS et al., 1998), tornando-se ferramentas que devem relacionar os diversos conceitos pertinentes a uma temática. Os professores que buscam esta perspectiva interdisciplinar devem considerar que os conhecimentos não devem ser vistos individualmente, mas a partir de um tema estruturador (MORIN, 1999; 2002)

Os assuntos abordados de forma isolada em disciplinas os tornam mais complexos, carentes de uma visão do todo. A fragmentação conceitual acaba tornando o ensino mecânico e repetitivo, de pouco valor para os estudantes. Sendo assim, a interdisciplinaridade como atitude do professor, tem a potencialidade para ligar os conceitos e auxiliar em sua compreensão, sem destruir as especificidades de cada ciência (ETGES, 1995; SALVADOR, 2006). As interconexões conceituais entre as disciplinas devem ser realizadas. Ao fazermos com que o aluno reflita e tome consciência de que o conhecimento é uma ferramenta de mudança, ele torna o ensino mais significativo (GASPARIAN, 2006).

Nesta intervenção, a atitude docente interdisciplinar se dá quando este busca os conhecimentos de mais de uma área para melhor abordar Energia que atua como assunto articulador do processo de ensino. A vivência dos sujeitos da EJA, foco deste trabalho, é extremamente rica já que estão imersos em diversos meios, como familiar, social e de trabalho (COIMBRA et al., 2009), mesmo que atualmente o público alvo da modalidade seja mais jovem, já que muitas vezes estes alunos migram do ensino regular, ao completarem 18 anos. Em decorrência da ampla participação e inserção na sociedade, estes jovens e adultos apresentam inúmeras ideias prévias que devem ser consideradas pelo professor em seu planejamento, pois auxiliam no desenvolvimento e avaliação de suas aulas.

Assim, é necessária a preocupação de que pesquisadores da área de Ensino realizem, previamente ao desenvolvimento das intervenções, um mapeamento do que os sujeitos da pesquisa já compreendem sobre o tema. Isto auxilia na construção das estratégias, bem como é essencial para avaliar se houveram indícios de evoluções conceituais.

\section{A Teoria da Aprendizagem Significativa}

Os três pressupostos básicos da aprendizagem significativa (AS) abordados por Ausubel et al. (1980; 2003), nortearam este estudo: o desenvolvimento de um material potencialmente significativo, a estrutura cognitiva preexistente ser considerada durante as atividades e o estímulo da predisposição do aluno em querer aprender. Ensino e aprendizagem, segundo estes referenciais, estão relacionados de modo intrínseco, ou seja, não possuem existência isolada quando se almeja implementar intervenções significativas. $\mathrm{O}$ mapeamento das concepções iniciais é a variável fundamental quando se deseja analisar a efetividade de uma proposta de ensino.

Concepções de senso comum podem se tornar obstáculos para aprendizagem. Contudo, o professor deve mediar o ensino de modo a negociar significados, problematizando os conceitos e tornando a aprendizagem mais significativa. Isto ocorre quando a proposição toma um significado pelo aluno quando ele busca em sua estrutura cognitiva, conceitos âncora, chamados "subçunsores" (MOREIRA, 1998).

As ideias prévias, de acordo com a A.S, possuem níveis de clareza e diferenciação, que são fundamentais para aquisição de novos conhecimentos, já que estas servem "de base para a atribuição de significados à nova informação, ele também se modifica." (MOREIRA, 1998, p.5). Neste sentido, ensinar é um processo envolvendo condições mínimas para que ocorram aprendizagens significativas: 0 material adequado, a motivação para aprender e conceitos prévios suficientes ao nível de dificuldade. Nesse sentido, para Ausubel o conhecimento prévio (estrutura cognitiva) é a variável fundamental para a ocorrência da aprendizagem significativa (ZOMPERO e LABURÚ, 2010). Contudo, só isso não basta. É necessário que o professor considere os desejos e motivações (interesses) de seus alunos, para proporcionar uma aprendizagem significativa (POZO, 1998). Esta vontade ou pré-disposição é necessária, pois aprender requer sempre um esforço do sujeito em superar suas limitações.

Cada contexto de ensino seja a modalidade, o tipo de escola, localização e público-alvo, 
necessita ser considerado. Neste sentido, fazer uma investigação prévia dessas realidades é fundamental. O uso de temáticas na EJA, que contextualizem os assuntos e os tornem mais próximos da realidade dos educandos, mostra-se também como alternativa a abordagens mais tradicionais.

Quando se começa a articular, pelo aluno e professor, os conhecimentos prévios e novos, temos os primórdios da construção de uma aprendizagem mais significativa. Salienta-se que inexiste a possibilidade de abandonar completamente determinados conceitos em lugar de outros. O contexto de vida dos alunos não necessita muitas vezes compreensões muito profundas sobre determinado fenômeno observado. As ideias de senso comum ou concepções alternativas (cultura primeira), segundo Moreira (2011) foram elaboradas significativamente, o que torna difícil que sejam removidas ou "esquecidas" da memória dos alunos. Elas foram incorporadas a estrutura cognitiva de forma não literal e não arbitrária. Inexiste, nesse sentido, a perda ou abandono completo de idéias alternativas e aquisição somente daqueles significados mais adequados cientificamente, "Poder-se-ia pensar a mudança conceitual como uma evolução conceitual" (op cit., p.183). O estudante, ao final de uma intervenção didática, apresenta ainda ideias alternativas, porém, ele faz acréscimos a partir das novas informações e se espera que ao final do processo essas mudanças sejam mais definitivas e fixas, tornando a compreensão final mais adequada para compreensão do mundo a sua volta.

A construção de significados, pelo homem, se dá de forma mais eficiente quando ele aprende primeiro aspectos mais globais e inclusivos de um assunto, em vez de analisar primeiramente os seus aspectos mais específicos e pontuais (TAVARES, 2008). Assim, deve-se partir do princípio chamado de diferenciação progressiva, no qual os conceitos mais gerais e inclusivos de um assunto são apresentados inicialmente para, na sequência, de forma progressiva, apresentar as partes mais específicas, seus detalhes (AUSUBEL, 2003). A partir desta perspectiva, se garante que os estudantes possam mais facilmente adquirir conhecimentos diferentes, pois tem a visão do todo no princípio e não apenas no final do processo.
É mais fácil aprender, nesse sentido, conceitos específicos quando se inicia apresentando visões mais gerais e que englobam os conceitos menores, inclusos no tema. Os conhecimentos em fragmentos, sem apresentar primeiramente o geral, tornam difícil a compreensão e conseqüente aprendizagem. Assim, ao se trabalhar de forma interdisciplinar, não apenas abordando aspectos específicos de um assunto, pode-se favorecer e estimular a construção do conhecimento.

Cada estudante aprende de forma diferente, já que sua estrutura cognitiva é reflexo das suas experiências prévias. Os conceitos mais inclusivos (gerais) ocupam posições maiores na rede hierárquica das informações que englobam, na sequência, as proposições de significado mais específicas, que apresentam situações mais pontuais. Neste sentido, considerar estes conceitos prévios é fundamental para possibilitar uma aprendizagem mais significa que promova evoluções conceituais ao final do processo.

\section{Metodologia, Resultados e Discussão}

Nosso estudo objetivou determinar, inicialmente, quais eram as ideias dos estudantes sobre o conceito de Energia antes da intervenção e também utilizar estas informações para elaborar um material potencialmente significativo. Ao final, se comparou a estrutura cognitiva com o observado antes do desenvolvimento da estratégia.

Foram elaborados três instrumentos básicos da pesquisa, a qual foi desenvolvida com um total de 43 estudantes de duas turmas de EJA (etapas 8 e 9, correspondentes ao ciclo final do ensino médio) de uma escola pública do município de Santa Maria - RS. O primeiro instrumento, Perfil SócioEducacional e de Interesses, consistiu de um questionário com perguntas aberto-fechadas cujo foco foi determinar algumas características do público alvo da pesquisa, como interesses em determinadas estratégias metodológicas de ensino, hábitos de leitura, idade dos participantes, características relacionadas ao tempo que permaneceram fora da escola; além dos alunos apontarem o nível de relevância a algumas questões- 
problema de energia, elaboradas pelos autores, que eles gostariam de aprender e solucionar durante as aulas que seriam desenvolvidas posteriormente.

O segundo instrumento, Investigação de Concepções iniciais sobre Energia, objetivou determinar quais os significados que os estudantes atribuíam ao conceito antes da realização da intervenção. Além disso, estas informações foram utilizadas para construir um módulo didático que potencialmente se relacionasse aos conhecimentos prévios dos alunos, de forma não arbitrária e não literal, para que o referido material fosse significativo e auxiliasse na evolução conceitual dos alunos.

A proposta de ensino, organizada em 8 atividades didáticas que utilizaram inúmeras estratégias metodológicas, pode ser consultada em detalhes no corpo da dissertação (TASCHETTO, 2014) e está resumidamente descrita na Figura 4.

Por fim o último instrumento, além daqueles que compuseram as avaliações individuais de cada uma das atividades planejadas e desenvolvidas, foi o Questionário de Avaliação final da Aprendizagem, do qual, em conjunto com a análise dos demais instrumentos, propiciou obtermos indícios da aprendizagem significativa, relacionada com a evolução conceitual obtida pelos alunos (MOREIRA, 2011). Os dados dos questionários escritos, que apresentavam perguntas abertas, foram analisados conforme a metodologia da Análise Textual Discursiva - ATD (MORAES \& GALIAZZI, 2007).

\subsection{Determinação de interesses e perfil socioeducacional}

Com o objetivo de determinar um perfil socioeducacional dos estudantes participantes da pesquisa, foi construído um instrumento para coleta de dados com questões do tipo aberta e fechadas. O referido objeto de coleta de informações foi elaborado na forma de questionário com perguntas abertas e fechadas que abordou gênero, idade, estado civil, profissão, renda, $\mathrm{n}^{\mathrm{o}}$ de filhos, acesso à internet, hábitos de leitura e campos do conhecimento de maior interesse. Além disso, também possíveis perguntas que eles gostariam de compreender sobre a temática Energia. Este primeiro instrumento teve o objetivo, além de fazer um delineamento do perfil sócio-educacional das duas turmas de EJA participantes da pesquisa, um levantamento dos interesses dos estudantes relacionados à Energia. Posteriormente, este material auxiliou na construção das atividades de ensino que potencialmente fizessem significado e despertassem interesse nos alunos participantes.

Neste trabalho apresentaremos os resultados mais relevantes, que sintetizam os dados obtidos no estudo da dissertação de mestrado (TASCHETTO, 2014). Dados mais detalhados podem ser consultados no corpo do trabalho. Destacaremos duas análises importantes desta primeira etapa da pesquisa, que foram mais especificamente abordadas em um primeiro manuscrito (TASCHETTO \& GARCIA, 2014). Nosso enfoque neste trabalho, como salientado, é fazer uma avaliação da evolução conceitual. Primeiramente, a partir dos resultados apresentados nas Figuras 2 e 3, pode-se constatar o pouco interesse relacionado à disciplina de Física, dentro do campo das Ciências naturais.

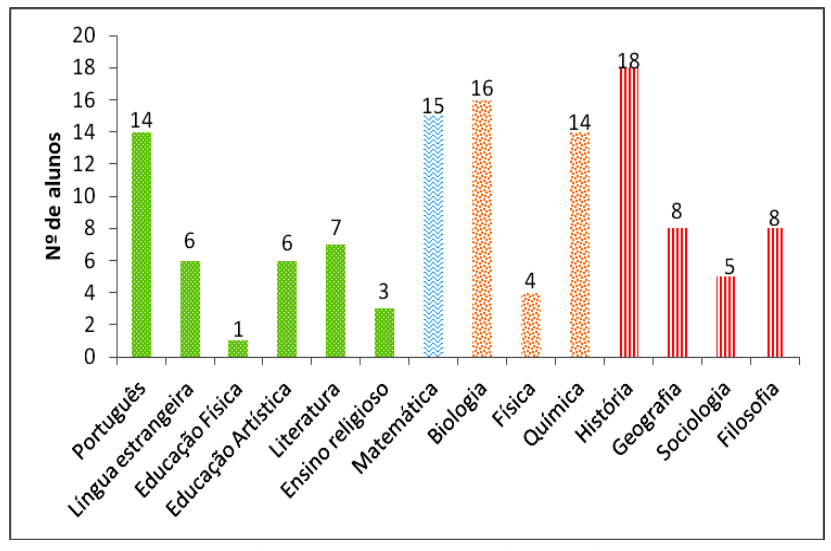

Figura 2. Grau de Interesse por disciplinas

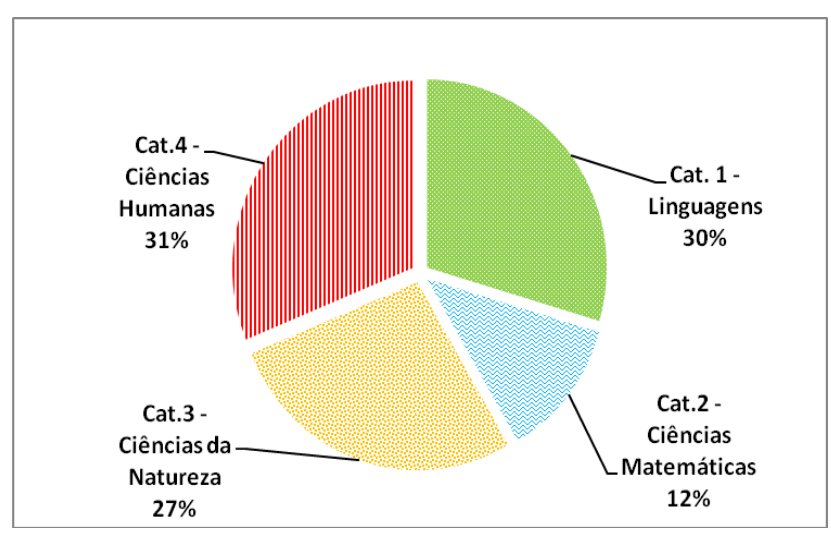

Figura 3. Interesse por áreas de conhecimento 
Provavelmente, este resultado é resultante, em partes, pois tradicionalmente os professores abordam os conceitos pouco relacionados com o contexto dos alunos. Além disso, possivelmente as estratégias que os alunos estão habituados não os motivam a querer aprender os conceitos e temas apresentados por esta disciplina. Especificamente, em relação ao interesse por Biologia e Química, a maior parte, considerou estarem satisfeitos com as perspectivas apresentadas pelos docentes.

A tabela 1 sintetiza os dados relacionados ao interesse dos estudantes em relação a exemplos de alguns tipos de abordagens / estratégias de ensino desenvolvidas em sala de aula pelo professor. Nosso objetivo foi considerar, como já salientado, o querer aprender destes jovens. Neste sentido, foi necessário compreender quais eram perspectivas metodológicas que eles mais se interessavam em participar nas intervenções.

Tabela 1. Relevância da utilização de estratégias

\begin{tabular}{|l|c|c|}
\hline \multicolumn{1}{|c|}{ Atividade } & $\begin{array}{c}\text { Menor } \\
\text { Interesse }\end{array}$ & $\begin{array}{c}\text { Maior } \\
\text { Interesse }\end{array}$ \\
\hline A - Quadro e giz & $46 \%$ & $54 \%$ \\
B - Retroprojetor & $63 \%$ & $37 \%$ \\
C - Slides & $54 \%$ & $46 \%$ \\
D - Livro Didático & $54 \%$ & $46 \%$ \\
E - Folhas xerocadas & $30 \%$ & $70 \%$ \\
F - Experimentos & $37 \%$ & $63 \%$ \\
G- Vídeos & $24 \%$ & $76 \%$ \\
H - Laboratório de & $9 \%$ & $91 \%$ \\
Informática & $37 \%$ & $63 \%$ \\
I - Aulas Dialogadas & $59 \%$ & $41 \%$ \\
J - Jogos didáticos & $48 \%$ & $52 \%$ \\
K - Apresentação & \\
Trabalhos & \multicolumn{2}{|c}{} \\
\hline
\end{tabular}

Uma escala do tipo likert foi utilizada, sendo que os índices 1 e 2, referiam-se ao menor interesse pela atividade, e 3 e 4, ao maior interesse em participar de uma aula utilizando determinada estratégia. $\mathrm{O}$ uso do laboratório de informática, o diálogo como prática de ensino, a utilização de experimentos e a proposição de trabalhos de pesquisa / apresentação, foram as categorias que os estudantes tiveram maior interesse. $\mathrm{O}$ uso de retroprojetor e jogos didáticos apresentou $\mathrm{o}$ menor índice de aceitação

A parte final do questionário solicitava que os estudantes indicassem quais eram seus interesses relacionados à temática energia. Então, foram produzidas questões prévias sobre o assunto, as quais foram organizadas em 4 categorias. A partir da análise destas respostas, foi construído, posteriormente, o conjunto de atividades didáticas, que consideraram também o querer aprender dos sujeitos da pesquisa. Analogamente, foi utilizada uma escala likert, na qual o percentual negativo (\%-) se refere ao somatório de marcações em "1 e 2", que representam o menor interesse e " $\%+$ " denota a soma do maior interesse " 3 e 4". (Tabela 2).

A categoria $\mathrm{n}^{\mathrm{0}} 4$ Combustíveis e Armamentos somou o menor índice de interesse, com $82 \%$ admitindo terem pouco desejo em compreender as relações de energia com a indústria bélica e de abastecimento. As categorias 1 e 2, Corpo humano e Sustentabilidade, somaram o maior interesse pelos estudantes. Por esse motivo, elas foram selecionadas para a construção do módulo didático. Alguns questionamentos destas categorias, que estavam no instrumento de investigação, foram:

- Como o sol influencia nosso dia a dia?

- Quais as relações de energia com as sensações de frio e calor?

- Cotidianamente, como podemos ter práticas para manter os recursos da Terra?

- A água pode ser utilizada como origem energética?

- Como pode ser gerada eletricidade a partir dos ventos?

- O que é Energia?

Tabela 2. Categorias das questões sobre energia

\begin{tabular}{|c|c|c|c|c|c|c|}
\hline CATEGORIAS & [1] & [2] & $\%-$ & [3] & [4] & $\%+$ \\
\hline Categoria 1: Corpo Humano & $18 \%$ & $9 \%$ & $27 \%$ & $13 \%$ & $60 \%$ & $73 \%$ \\
\hline Categoria 2: Sustentabilidade & $13 \%$ & $24 \%$ & $38 \%$ & $49 \%$ & $13 \%$ & $62 \%$ \\
\hline Categoria 3: Meio ambiente & $7 \%$ & $40 \%$ & $47 \%$ & $40 \%$ & $13 \%$ & $53 \%$ \\
\hline Categoria 4: Combustíveis/Armamentos & $60 \%$ & $22 \%$ & $82 \%$ & $4 \%$ & $13 \%$ & $18 \%$ \\
\hline
\end{tabular}


4.2 Investigação de concepções iniciais sobre Energia

A dificuldade de conceituar Energia é uma das principais causas para a existência de uma extensa lista de ideias prévias sobre seu significado, sendo que a maioria delas apresenta visões pouco adequadas e simplistas.

Contudo, podemos afirmar com certeza aquilo que não pode ser definido por Energia, com a finalidade primordial de discernir os conceitos aceitos cientificamente daqueles inadequados, com base no senso comum (GASPAR, 2009). A partir dos avançados estudos da Física moderna (EISBERG \& RESNICK, 1979), houve o descobrimento de que Energia e Massa são permutáveis entre si, isto é, uma pode ser transformada na outra. Esta relação ficou evidenciada mais claramente no enunciado proposto por Einstein de que Energia é igual a soma do quadrado da velocidade da luz versus o valor de massa $\left(\mathrm{E}=\mathrm{m} \cdot \mathrm{c}^{2}\right)$.

Em nosso cotidiano, podemos utilizar este conceito em diferentes contextos e muitas vezes com diversos significados. Contudo, seu entendimento é muito fragmentário, não existe uma consonância para responder, afinal, "O que é Energia?" (RUSSO, 2007). Neste estudo, as ideias que consideramos mais adequadas, apontadas pelos sujeitos da pesquisa em resposta as intervenções implementadas, são as que a definem o conceito como:

- Energia é a capacidade potencial de gerar mudanças, ou seja, a possibilidade de produzir transformações;

- Energia pode ser compreendida pela observação de suas inúmeras fontes e formas, bem como pelos recursos e avanços tecnológicos / industriais necessários para realizar sua exploração, fomentando o desenvolvimento econômico $e$ social;

- A energia flui de um local para outro, sempre se conservando.

No estudo de Coimbra et al. (2009), os conhecimentos prévios dos estudantes sobre a temática foram considerados no desenvolvimento da prática na escola. Os dados, obtidos através de respostas a questões do Exame Nacional do Ensino Médio - ENEM, foram analisados a partir da observação de evoluções conceituais resultantes do trabalho de mediação exercido pelo docente durante a implementação da estratégia de ensino utilizada por estes autores. Vieira (2011), em sua pesquisa, analisou matematicamente os resultados de sua intervenção a partir de questões que apresentavam escalas do tipo likert, para afirmarem o quão verdadeiras eram as proposições.

Em estudo de revisão de literatura sobre ideias prévias relacionadas ao conceito de Energia, Castro e Mortale (2012), sintetizaram as pesquisas da área sobre esse assunto, agrupando em uma lista as concepções mais comuns atribuídas ao seu significado. Emergiram as seguintes categorias: Funcionalidade, Materialismo, Movimento, Fluxo, Esoterismo, Energia nos seres vivos, Transformação, Reducionismo, Origem e Outras. O grande número de significados atribuídos ao conceito de Energia é, segundo os autores, resultante da perspectiva fragmentada que é abordado em sala de aula, visto pontual e isoladamente, denotando que a Energia abordada em uma disciplina não apresenta nenhuma conexão com as demais.

Para Lancor (2014) esta compreensão diversa dada à Energia, pelas diferentes áreas do conhecimento, torna o seu entendimento inadequado. Sendo assim, ocorre o aparecimento de inúmeras concepções: como substância que pode ser contada, como capacidade de alternar a forma, com a possibilidade de sofrer perdas / gastos, como reagente / produto de reações e suas interações com o meio ambiente.

Como dito previamente, o mapeamento das concepções iniciais é de extrema importância quando se almeja obter indícios de que os estudantes evoluíram conceitualmente e, ao final do processo, apresentam uma visão mais ampla e adequada. De acordo com o referencial adotado neste estudo, os conceitos novos, mais próximos das visões da ciência, são negociados e incluídos de forma gradativa na estrutura cognitiva dos estudantes. Ampliar o perfil conceitual dos estudantes, contribuindo com explicações mais próximas da realidade em constante ligação com as ideias prévias, deve ser o foco de atividades que visem proporcionar aprendizagens significativas (MORTIMER, 1996). 
4.3 Análise Textual Discursiva (ATD) e o processo de categorização

Após aplicação do instrumento inicial que determinou os interesses e perfil dos pesquisados, foi elaborado um questionário com questões abertas para investigar as concepções iniciais relacionadas à Energia, como mencionado anteriormente. Os dados foram analisados e categorizados a partir da Análise textual discursiva - ATD (MORAES \& GALIAZZI, 2007). A análise criteriosa dos dados obtidos do corpus da pesquisa proporcionou um intenso processo de reflexão e, como resultado, emergiram as categorias da análise, bem como a frequência destas. A partir do estudo de revisão de literatura (CASTRO \& MORTALE, 2012), utilizamos como forma metodológica de análise o estabelecimento a priori das categorias. Estas, dessa forma, funcionaram como "caixas", nas quais as unidades de sentido são organizadas (MORAES, 2003). O processo de análise se tornou mais claro e foi facilitado o entendimento da cultura inicial dos estudantes sobre Energia, separando seus discursos conforme a categoria adequada.

Além de identificar as concepções iniciais (critério qualitativo), nos preocupamos em estabelecer a quantidade de discursos em cada categoria com o intuito de perceber quais ideias eram as mais freqüentes. A partir desses dados, foi possível trabalhar posteriormente com as ideias mais comuns que poderiam representar obstáculos para a aprendizagem significativa do significado de energia.

$\mathrm{Na}$ Tabela 3 apresentamos as categorias emergentes da análise definidas a priori pela literatura, as quais sofreram modificações para melhor retratar os discursos dos estudantes, e também os respectivos índices (caráter quantitativo da análise). Constatou-se que a maioria dos alunos apresentava mais de um tipo de discurso sobre energia. Assim, a quantidade de respostas não corresponde à soma total de sujeitos que participaram desta etapa do estudo (50 alunos). As Categorias Movimento e Vida foram as que apresentaram maior índice. Nelas, os sujeitos consideram que energia está relacionada à possibilidade de realizar trabalho e as questões biológicas que envolvem o termo, considerando sua essencialidade para a sobrevivência da humanidade. A seguir, temos Reducionismo, Origem e Transformação. As duas primeiras exemplificam como obter energia, sendo que ao dar um único exemplo, o aluno reduz a compreensão do significado do conceito na observação de apenas um fenômeno. Já em Origem, trazem inúmeras fontes, denotando a compreensão da existência de inúmeras origens e formas. Em Transformação afirmam que a Energia está constantemente se alternando de forma, nunca podendo ser criada ou destruída, mas em sua totalidade conservada. Esta concepção apresenta indícios da compreensão da perspectiva conservacionista de seu significado. Em Materialismo englobam-se enunciados que usam vocábulos como gerar, gastar, degradar ou ver a Energia. Associam ao seu significado características materiais como ser medida através de massa e apresentar um volume. Em Funcionalidade é associada à ideia de que ela é necessária para o funcionamento de aparelhos ou sistemas para poderem ser ligados e funcionarem, como exemplo, um televisor ou qualquer outro eletrodoméstico. Em Fluxo, se considera energia como algo a ser transferido para outro meio. Finalmente, as Categorias Aconceitual e Branco denotam, respectivamente, a afirmação da inexistência de um conceito adequado para seu entendimento e os alunos que não responderam à questão proposta.

Objetivando que ao final do processo os estudantes alvo desta pesquisa evoluíssem conceitualmente em relação à Energia, construíram-se um conjunto de atividades com a potencialidade de estabelecer relações "âncora" dos conhecimentos novos com as ideias alternativas iniciais. Os conflitos cognitivos, evidenciados através da problematização de questões do dia a dia, fez com que os alunos observassem que suas ideias não eram suficientes para entender determinados fenômenos naturais. Partindo de uma perspectiva global do assunto, abordando-o de forma genérica inicialmente, se pode superar as concepções Esoterismo, Vida Aconceitual e Branco já na atividade inicial que trabalhou com textos de divulgação científica sobre energia (OLIVEIRA, 2009). A partir desta contextualização e diferenciação progressiva do assunto, foram planejadas as demais atividades com o intuito de evoluir as concepções Materialismo, Movimento e Funcionalidade. Na Figura 4, o conjunto de atividades desenvolvidas. 
Tabela 3. Exemplos de resposta para as categorias das Concepções prévias de Energia

\begin{tabular}{|c|c|c|c|}
\hline Categoria & Exemplo & Categoria & Exemplo \\
\hline \multirow[t]{2}{*}{$\begin{array}{l}\text { MOVIMENTO } \\
18,9 \% \\
17 \text { respostas }\end{array}$} & \multirow{2}{*}{$\begin{array}{l}\text { "Algo que pode modificar a matéria, } \\
\text { provar, anular momentos e ainda causar } \\
\text { sensações algo que não pode ser criado, } \\
\text { só transformado." TB22 }\end{array}$} & $\begin{array}{c}\text { MATERIALISMO } \\
7,8 \% \\
7 \text { respostas } \\
\end{array}$ & $\begin{array}{l}\text { "Energia é tudo aquilo que podemos } \\
\text { queimar e produzir energia." TB16 }\end{array}$ \\
\hline & & \multirow{3}{*}{$\begin{array}{c}\text { FUNCIONALIDADE } \\
4,4 \% \\
4 \text { respostas }\end{array}$} & \multirow{3}{*}{$\begin{array}{l}\text { "Energia é como se fosse a única fonte } \\
\text { de acontecer a eletricidade, sem energia } \\
\text { simplesmente não liga nem acende } \\
\text { nada." TA09 } \\
\text { "Podemos dizer que energia, nada mais } \\
e ́ \text { que uma fonte de carga, para algo } \\
\text { funcionar." TB8 }\end{array}$} \\
\hline $\begin{array}{c}\text { VIDA } \\
18,9 \% \\
17 \text { respostas }\end{array}$ & $\begin{array}{l}\text { "A energia é simplesmente o que move } \\
\text { tudo. O ser humano necessita de energia } \\
\text { para sobreviver em todos os aspectos." } \\
\text { TВ02 }\end{array}$ & & \\
\hline \multirow{2}{*}{$\begin{array}{l}\text { REDUCIONISMO } \\
14,4 \% \\
13 \text { respostas }\end{array}$} & \multirow{2}{*}{$\begin{array}{l}\text { "Um bom exemplo de energia é o sol, } \\
\text { uma "energia" que podemos sentir em } \\
\text { nosso rosto a milhões de quilometros de } \\
\text { distancia. Isso pode ser energia." TA12 }\end{array}$} & & \\
\hline & & & $\begin{array}{l}\text { "Enquanto um sistema ganha energia o } \\
\text { outro perde. Por isso, dizemos a energia }\end{array}$ \\
\hline \multirow[b]{2}{*}{$\begin{array}{l}\text { ORIGEM } \\
13,3 \% \\
12 \text { respostas }\end{array}$} & \multirow{2}{*}{$\begin{array}{l}\text { "Eu sei que temos mais de um tipo de } \\
\text { energia como a energia elétrica que vem } \\
\text { das usinas hidrelétricas, eólica, energia } \\
\text { vem através do sol, a energia cinética } \\
\text { que é a energia do movimento. "TA21 }\end{array}$} & 3 respostas & $\begin{array}{l}\text { não se perde totalmente, ela vai se } \\
\text { convertendo." TA24 }\end{array}$ \\
\hline & & $\begin{array}{c}\text { ACONCEITUAL } \\
3,4 \% \\
3 \text { respostas } \\
\end{array}$ & $\begin{array}{l}\text { "Não existe um conceito sobre energia, } \\
\text { mas um bom exemplo de energia é o } \\
\text { sol." TA12 }\end{array}$ \\
\hline \multirow{2}{*}{$\begin{array}{l}\text { TRANSFORMAÇÃO } \\
11,1 \% \\
10 \text { respostas }\end{array}$} & \multirow{2}{*}{$\begin{array}{l}\text { "Algo que pode modificar a matéria, [...] } \\
\text { e ainda causar sensações; algo que não } \\
\text { pode ser criado, só transformado." TB22 } \\
\text { "Que ela não se perde nem se ganha." } \\
\text { TA25 }\end{array}$} & $\begin{array}{l}\text { BRANCO } \\
3,4 \% \\
3 \text { respostas } \\
\end{array}$ & "Nada." TB3 \\
\hline & & $\begin{array}{c}\text { ESOTERISMO } \\
1 \% \\
1 \text { resposta }\end{array}$ & $\begin{array}{l}\text { "O ser humano necessita de energia } \\
\text { para sobreviver: solar, calórica } e \\
\text { espirita." TB9 }\end{array}$ \\
\hline
\end{tabular}

* Apresenta-se na cor laranja as ideias alternativas equivocadas; já em vermelho, concepções mais adequadas na visão científica.

\begin{tabular}{|c|c|c|c|}
\hline \multicolumn{4}{|c|}{ Descrição das Atividades do módulo didático Total: $23 \mathrm{~h} / \mathrm{a}$} \\
\hline Atividade & Assunto abordado e Descrição & Recursos e Estratégia & Avaliação \\
\hline $\begin{array}{l}\text { Atividade } 1 \\
\text { (A.1) } \\
\text { 2h/a }\end{array}$ & $\begin{array}{l}\text { Metodologia da Pesquisa aplicada } \\
\text { ao ensino médio: normas de como } \\
\text { realizar uma investigação; citação } \\
\text { de autoria e fontes. }\end{array}$ & $\begin{array}{l}\text { Quadro e giz; } \\
\text { impresso; } \\
\text { direta eriações } \\
\text { referências. }\end{array}$ & $\begin{array}{l}\text { Levantamento do } \\
\text { conhecimento prévio dos } \\
\text { alunos. }\end{array}$ \\
\hline $\begin{array}{l}\text { (A. 2) } \\
\text { Parte I } \\
\text { 2h/a }\end{array}$ & $\begin{array}{l}\text { Formas de energia em nosso } \\
\text { cotidiano: reconhecendo origens e } \\
\text { novas alternativas. }\end{array}$ & $\begin{array}{l}\text { Leitura de textos em } \\
\text { grupo (fragmentos); } \\
\text { debate sobre questões } \\
\text { energéticas. }\end{array}$ & $\begin{array}{l}\text { Participação em aula; } \\
\text { contribuições dos alunos; } \\
\text { questões. }\end{array}$ \\
\hline $\begin{array}{l}\text { (A.2) } \\
\text { Parte II } \\
\text { 2h/a } \\
\end{array}$ & $\begin{array}{l}\text { Alternativas Energéticas futuras: } \\
\text { apresentações dos grupos sobre as } \\
\text { novas formas de energia. }\end{array}$ & $\begin{array}{lr}\text { Material impresso; } \\
\text { Apresentação oral } \\
\text { pelos alunos (grupos). } \\
\end{array}$ & $\begin{array}{l}\text { Construção de } \\
\text { apresentação e resenha. }\end{array}$ \\
\hline $\begin{array}{l}\text { (A.3) } \\
\text { Parte I } \\
1 \mathrm{~h} / \mathrm{a}\end{array}$ & \begin{tabular}{l}
\multicolumn{3}{l}{ Relação de energia com os Estados } \\
da matéria: mudanças de \\
temperatura a partir do \\
fornecimento e retirada de calor.
\end{tabular} & $\begin{array}{l}\text { Sala de informática; } \\
\text { demonstração do uso } \\
\text { da } r \text { simulação } \\
\text { computacional (S.C) }\end{array}$ & $\begin{array}{l}\text { Participação em aula; } \\
\text { questionamentos. }\end{array}$ \\
\hline $\begin{array}{l}\text { (A.3) } \\
\text { Parte II } \\
\text { 2h/a } \\
\end{array}$ & $\begin{array}{l}\text { Identificação dos estados físicos a } \\
\text { partir da distância entre partículas: } \\
\text { uso da Simulação Computacional. }\end{array}$ & $\begin{array}{l}\text { Sala de informática; } \\
\text { trabalho coletivo de } \\
\text { análise de questões }\end{array}$ & $\begin{array}{lr}\begin{array}{l}\text { Organização; } \\
\text { escrito; }\end{array} & \begin{array}{r}\text { trabalho } \\
\text { interesse; }\end{array} \\
\text { participação. } & \\
\end{array}$ \\
\hline $\begin{array}{l}\text { (A.4) } \\
\text { Parte I } \\
1 \mathrm{~h} / \mathrm{a}\end{array}$ & $\begin{array}{l}\text { Uso de combustíveis e a Chuva } \\
\text { ácida: explorando as ideias prévias } \\
\text { sobre relações entre consumo e } \\
\text { degradação ambiental. }\end{array}$ & $\begin{array}{l}\text { Quadro e giz; figuras; } \\
\text { debates mediados pelo } \\
\text { professor. }\end{array}$ & $\begin{array}{l}\text { Participação; } \\
\text { questionamentos. }\end{array}$ \\
\hline
\end{tabular}

Figura 4: Quadro resumo das atividades construídas e desenvolvidas a partir de Energia na EJA. 
(Continuação)

\begin{tabular}{|c|c|c|c|}
\hline $\begin{array}{l}\text { (A.4) } \\
\text { Parte II } \\
3 \mathrm{~h} / \mathrm{a}\end{array}$ & 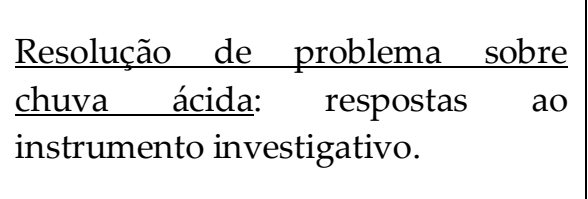 & $\begin{array}{l}\text { Material impresso; } \\
\text { Trabalho coletivo para } \\
\text { resolver a situação } \\
\text { problema. }\end{array}$ & $\begin{array}{l}\text { Resposta às questões } \\
\text { problema. }\end{array}$ \\
\hline $\begin{array}{c}\text { (A.5) - (A.6) } \\
5 \mathrm{~h} / \mathrm{a}\end{array}$ & $\begin{array}{l}\text { Tipos de Energia Limpa e suas } \\
\text { relações com o ambiente: debate a } \\
\text { partir de vídeos sobre questões } \\
\text { relacionadas à Energia } \\
\text { Construção de mapa conceitual: } \\
\text { elaboração pelos alunos. }\end{array}$ & $\begin{array}{l}\text { Quadro e giz; slides; } \\
\text { vídeos; Proposição de } \\
\text { questões sobre o tema } \\
\text { abordado nos filmes. }\end{array}$ & $\begin{array}{l}\text { Questionamentos; } \\
\text { participação; elaboração } \\
\text { do mapa conceitual. }\end{array}$ \\
\hline $\begin{array}{l}\text { (A.7) } \\
1 \mathrm{~h} / \mathrm{a}\end{array}$ & $\begin{array}{l}\text { Determinação de percentual de } \\
\text { álcool na gasolina: cálculo e } \\
\text { visualização da combustão de } \\
\text { amostras }\end{array}$ & $\begin{array}{l}\text { Quadro e giz; Slides; } \\
\text { aparato experimental; } \\
\text { Atividade } \\
\text { demonstrativa. }\end{array}$ & $\begin{array}{l}\text { Participação em aula; } \\
\text { Questionamentos; } \\
\text { Resenha. }\end{array}$ \\
\hline $\begin{array}{l}\text { (A.8) } \\
2 \mathrm{~h} / \mathrm{a}\end{array}$ & $\begin{array}{l}\text { Trabalho de pesquisa: resposta à } \\
\text { questão "Como o sol influencia a } \\
\text { sua vida?" }\end{array}$ & $\begin{array}{l}\text { Sala de informática; } \\
\text { Biblioteca; atividade } \\
\text { realizada em duplas. }\end{array}$ & $\begin{array}{l}\text { Trabalho escrito; } \\
\text { Participação nos grupos. }\end{array}$ \\
\hline Q.F 2h/a & Avaliação final (pós-teste). & Questionário. & Respostas escritas. \\
\hline
\end{tabular}

Figura 4: Quadro resumo das atividades construídas e desenvolvidas a partir de Energia na EJA.

\subsection{Análise da Evolução conceitual}

Para avaliar se os estudantes, ao final das atividades haviam avançado na compreensão do significado do conceito de Energia, foi elaborado um instrumento final (Q.F), a partir de questões abertas. Foi realizada a análise comparativa das respostas dos estudantes em relação à Energia dos instrumentos inicial e final (Pré e Pós- Teste).

As categorias de análise se basearam, além destes dois instrumentos, na verificação nos demais itens avaliativos entregues pelos alunos durante o desenvolvimento de todo o módulo, buscando possíveis indícios de aprendizagem significativa.

Inicialmente, as concepções Movimento e Vida eram as que apresentavam o maior índice (Figura 5). Após o desenvolvimento da intervenção, a partir de estratégias potencialmente significativas durante o período, se pode observar uma evolução conceitual no significado atribuído pelos alunos a este conceito. Ao final das atividades (Figura 6), a maioria associa energia a Transformação e Origem. Em suas respostas, apresentaram a idéia de que energia está sempre alternando entre suas formas, bem como se conserva ao final de processos físicos, químicos ou biológicos. Além disso, trouxeram inúmeros exemplos de usos e recursos energéticos, denotando uma compreensão amplificada e global de seu significado.

Na Tabela 4 estão organizados os níveis de avanço na estrutura cognitiva dos estudantes, que nos dão indícios da aprendizagem significativa. Esta análise foi baseada, como já salientado, na comparação de concepções no início e fim das atividades, além dos dados dos demais instrumentos avaliativos.

Constata-se que houve uma evolução bastante satisfatória, considerando que as categorias Evolução e Evolução Parcial totalizam aproximadamente $91 \%$. Pode-se concluir que, a partir das atividades desenvolvidas e mediadas pela atitude interdisciplinar do professor e dos pressupostos da aprendizagem significativa, proporcionaram uma compreensão mais adequada do conceito de Energia, denotando evoluções conceituais. Em relação à cat. Permanência, 3 já possuíam inicialmente a idéia adequada para Energia e apenas 1 manteve a ideia de senso comum.. Evidenciamos alguns 


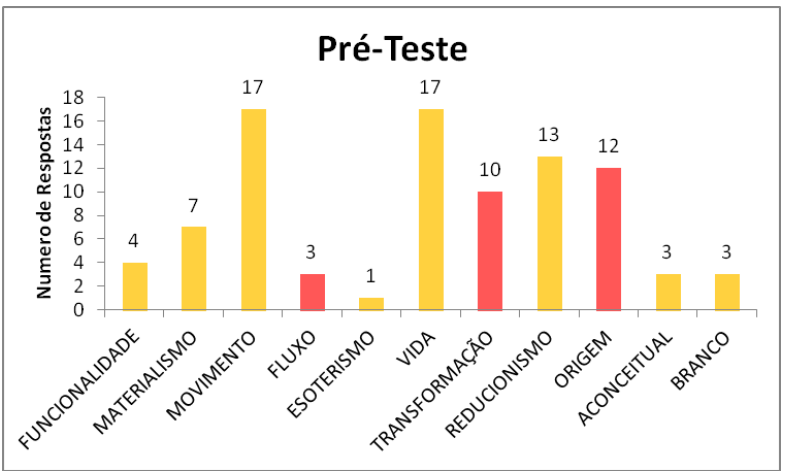

Figura 5. Categorias das idéias iniciais de Energia

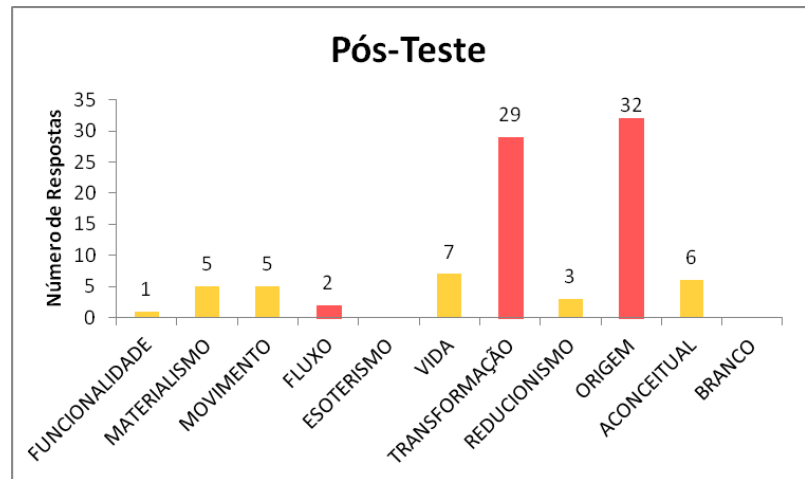

Figura 6. Significados atribuídos pelos alunos à Energia ao final das atividades.

Tabela 4. Avaliação da aprendizagem do conceito de Energia

\begin{tabular}{|c|c|c|}
\hline Categoria & Definição & Porcentagem \\
\hline EVOLUÇÃo & $\begin{array}{l}\text { Os estudantes avançaram significativamente em relação ao significado de } \\
\text { Energia. Os indícios de aprendizagem denotam que houve avanços na } \\
\text { estrutura cognitiva, quando comparados as suas concepções inciais. }\end{array}$ & $\begin{array}{l}23 \\
\text { estudantes } \\
53,5 \%\end{array}$ \\
\hline $\begin{array}{l}\text { EVOLUÇÃO } \\
\text { PARCIAL }\end{array}$ & $\begin{array}{l}\text { Os discursos, ao final, apresentam as categorias Transformação e Origem. } \\
\text { Contudo, algumas idéias relacionando energia a movimento, matéria e } \\
\text { funcionalidade ainda permanecem, refletindo um avanço parcial. }\end{array}$ & $\begin{array}{c}16 \\
\text { estudantes } \\
37,2 \% \\
\end{array}$ \\
\hline PERMANÊNCIA & $\begin{array}{l}\text { Não apresentam evolução nas concepções. Alguns já apresentavam o } \\
\text { conceito de transformação de energia e outros não as modificaram. }\end{array}$ & $\begin{array}{l}4 \text { estudantes } \\
9,3 \%\end{array}$ \\
\hline
\end{tabular}

* Total de estudantes que responderam ao questionário final: 43

exemplos da evolução conceitual obtidos pelos alunos, a partir da análise dos dados resultantes da pesquisa.

O aluno "TA1", inicialmente, admitia que energia era "Tudo que possui movimento, possui Energia," C. Movimento. Ao término das atividades, considerou que "Energia não pode ser tocada, não se perde, se transforma. Existem muitas fontes de conversão de energia: sol, hídrica, ar, etc." C. Transformação - Origem. Constata-se uma Evolução conceitual já que não mais relaciona energia apenas com aspectos físicos, mas a partir da concepção de transformação que este conceito apresenta. Já TA10 considerava no pré-teste que energia era "Tudo que gera luz, força e movimentos" $C$. Movimento - Reducionismo. Ao final, "Energia é tudo que é aproveitado pelos homens. A elétrica é uma das menos poluentes, temos outros exemplos como termoelétrica, eólica, nuclear e mecânica." C. Origem. Nota-se uma Evolução Parcial, pois houve um avanço, considerando as diferentes formas que energia se apresenta. Para o estudante TA19 "Tudo que tem movimento e gera eletricidade." C. Movimento Reducionismo (pré-teste) e "Energia é sempre associada à execução de alguma trabalho, que é realizado por transformações de energia de uma forma para outra ou de um lugar para outro." $C$. Transformação - Origem - Fluxo. (pós-teste). Percebe-se também uma Evolução já que admite que energia tem propriedades como fluir e sempre se transformar.

\section{Considerações finais e Conclusão}

Previamente à implementação das estratégias didáticas baseadas em Energia, descritas detalhadamente na Figura 4, construídas a partir dos interesses dos alunos, foi utilizado um instrumento para investigar as concepções iniciais destes relacionadas ao conceito trabalhado. Partindo destas ideias, foi possibilitada a abordagem numa perspectiva de negociação de significados, sendo que os conhecimentos prévios funcionaram como âncoras para as novas informações.

A partir da verificação e análise das respostas dos alunos às atividades propostas, foi possível obter evidências de que estes evoluíram conceitualmente, compreendendo mais adequadamente o significado de Energia. Além disso, consideramos, no fazer pedagógico em sala de aula, os aspectos mais humanos da aprendizagem, levando em consideração a 
motivação, o interesse e o prazer em aprender determinados conteúdos.

A avaliação da aprendizagem se deu de forma contínua. A partir dos dados coletados, foi possível obter esses resultados que apontaram a necessidade de trabalho a partir de uma atitude interdisciplinar do professor e, também, o conhecimento por este das ideias iniciais dos estudantes em relação à Energia, primordialmente. Os significados de senso comum relacionados ao conceito abordado não são totalmente abandonados ao final das atividades, mas sim existem acréscimos à estrutura cognitiva. Feita a comparação dos gráficos (Figuras 4 e 5), nota-se que foi superada a concepção que associava energia aos seres vivos e a movimentos. No final das atividades, se observa que os alunos agora compreendem que energia tem inúmeras origens e está relacionada a constantes mudanças entre suas formas (C. Transformação e Origem).

Sobre o consumo de recursos energéticos, todos os estudantes após a intervenção compreenderam que algumas fontes têm reservas que se esgotarão futuramente. Em relação à influência do uso de recursos energéticos, a partir das atividades didáticas desenvolvidas, compreenderam as relações diretas entre o uso de Energia e consequências ambientais negativas nos ecossistemas aquático, terrestre e aéreo. Também se proporcionou um entendimento do menor impacto que os combustíveis "limpos" causam aos ecossistemas.

As atividades aplicadas abordaram energia de uma forma amplificada. Ao usarmos um assunto como articulador do conhecimento,se partiu para a busca das informações necessárias nas diversas disciplinas para melhor compreendê-lo, denotando a perspectiva interdisciplinar atitudinal do docente ao preparar e desenvolver suas estratégias didáticas de ensino, cujo objetivo primordial foi a aprendizagem significativa. Ao abordar o conceito de energia de vários ângulos, se melhora o seu entendimento.

Novas investigações na área de Educação em Ciências, voltadas para a EJA, devem ser realizadas com o propósito de melhor compreender os contextos em que a modalidade se insere, bem como o interesse e perfil destes jovens.

\section{Referências}

ARAUJO, M. C. P de; NONENMACHER, S. Energia: um conceito presente nos livros didáticos de Fís., Bio. e Quím. no ensino médio. Poésis. v. 2, n. 1, p.1-13, 2009.

AUSUBEL, D.P.; NOVAK, J.D.; HANESIAN, H. Psicologia educacional. Tradução Eva Nick. Rio de Janeiro: Interamericana, 1980.

Aquisição e retenção do conhecimento: uma perspectiva cognitiva. Lisboa: Plátano edições técnicas, 2003.

BARBOSA, J,P.V; BORGES, A.T. O entendimento dos estudantes sobre energia no início do ensino médio. Cad. Bras. Ens. Fís. v. 23, n. 2: p. 182-217, 2006.

BESSON, U.; AMBROSIS, A. Teaching Energy Concepts by Working on Themes of Cultural and Environmental Value. Science \& Education. v.23, n.6, p. 1309-1338, 2014.

BOFF, E.T.; et al. Situação de Estudo: Uma possibilidade de Reconstrução de Teorias e Práticas Docentes. In: GALIAZZI, M.C. et al (orgs). Aprender em rede na educação em ciências. Ijuí: Ed.Unijuí, p.91-112, 2008.

BOSQUILA, G.E.; et al.; Interações e transformações I - Elaborando conceitos sobre transformações Químicas. São Paulo: Ed. da Universidade de São Paulo, 2012.

BUSQUETS, M.D.; et al. Temas Transversais em Educação: Bases para a formação integral. São Paulo: Ática, 1998.

CASTRO, L.P.S.; MORTALE, T.A.B. Energia: levantamento de concepções alternativas. 2012. 114f. Monografia. Mackenzie, SP, 2012.

COELHO, R.L. On the Concept of Energy: Eclecticism and Rationality. Science \& Education. v. 23, n.6, p. 1361-1380, 2014.

COIMBRA, D.; GODOI, N.; MASCARENHAS, Y. P. EJA: uma abordagem transdisciplinar para o conceito de energia. Enseñanza de lãs ciencias. v. 8, n.2, 2009.

ETGES, N.J. Ciência, Interdiscip. e Educação. In: JANTSCH, A.P.; BINCHETTI,L. (orgs). Interdisciplinaridade: para além da filosofia do sujeito. Petrópolis: Vozes, p.51-84, 1995. 
GASPAR, A.Experiências de Ciências. São Paulo: Ed. Ática, 2009.

GASPARIAN, M.C.C. Interdisciplinaridade e as questões da aprendizagem. In: FAZENDA, I. Interdisciplinaridade na formação de professores: da teoria à prática. Canoas: Ed.Ulbra, 2006. p. 103-111.

JACQUES, V.; MILARE, T.; FILHO. A presença do conceito de energia no tratamento de Química em livros didáticos de ciências. In: VII Encontro Nacional de Pesquisa em Ed. Ciências. Florianópolis - SC, 2009.

LANCOR, R. Using Metaphor Theory to Examine Conceptions of Energy in Biology, Chemistry, and Physics. Science \& Education. v. 23, n.6, p. 1245-1267, 2014.

MACHADO, A. R.; et al.. Processos de retomada e (re) significação do conceito de energia em aulas de física do EM. Ensino de Ciências e Tecn. em Rev. v.1, n.1, p. 15-21, 2011.

MORAES, R. Uma tempestade de Luz: a compreensão possibilitada pela Análise Textual Discursiva. Ciência \& Educação. v. 9, n. 2, p. 191-211, 2003.

; GALIAZZI, M. C. Análise textual discursiva. Ijuí: Unijuí, 2007.

Cotidiano no Ensino de Química: superações necessárias. In: GALIAZZI, M, C et al.(orgs). Aprender em rede na educação em ciências. Ijuí: Ed.Unijuí p.15-34, 2008.

MOREIRA, M.A. Teorias da Aprendizagem. $2^{a}$ Ed. São Paulo: EPU, 2011.

Mapas conceituais e aprendizagem significativa. Cadernos de Aplicação. v.11, n.2, p.143-156, 1998

MORIN, E. Da necessidade de um pensamento complexo. In: MARTINS, F. M; SILVA, J.M (orgs). Para navegar no século XXI. Porto Alegre: Sulina/Edipucrs, 1999.

A cabeça bem feita: repensar a reforma, reformar o pensamento. Rio de Janeiro: Ed. Bertrand Brasil, 2002.

MORTIMER, E.F. Evolução do Atomismo em Sala de Aula: Mudança de Perfis Conceituais. Tese de Doutorado, São Paulo, 1996.
OLIVEIRA, A. A energia em nossas vidas. 2009. Disponível em: http://cienciahoje.uol.com.br/colunas/fisicasem-misterio/a-energia-em-nossas-vidas > Acesso em: 15. Abr..2015.

POZO, J.I Teorias Cognitivas da Aprendizagem. Porto Alegre: Artes Médicas, 1998.

RUSSO, M.E. Energia e Movimento. Buenos Aires: Editorial Sol 90, 2007.

SALVADOR, C. M. Interdisciplinaridade no ensino Fundamental. . In: FAZENDA, I (orgs). Interdisciplinaridade na formação de professores: da teoria à prática. Canoas: Ed.Ulbra, p. 113-124, 2006.

TASCHETTO, A.G. Abordagem Interdisciplinar a partir da Temática Energia: Contribuições para uma Aprendizagem Significativa na EJA. 325f. Dissertação, PPG Educação em Ciências, UFSM, Santa Maria, 2014. Disponível em: $<$ http://cascavel.cpd.ufsm.br/tede/tde_busca/a rquivo.php?codArquivo=6536>

TASCHETTO, A.G. ; GARCIA, I.K. . Perfil sócioeducacional de estudantes da Educação de Jovens e Adultos (EJA): um estudo de realidades e interesses acerca do conceito Energia. Latin - American Journal of Physics Education, v. 8, p. 475-486, 2014.

TAVARES, R. Aprendizagem significativa e o ensino de ciências. Ciência e Cognição, v.18, p.94-100, 2008.

VIEIRA, M.A. Análise de concepções de alunos: uma visão da energia no contexto da Ed. Amb. In: V Col. Int. "Educação e Contemp.", São Cristóvão -SE, 2011.

ZANETIC, J. Física e cultura. Cienc. Cult. (online). v.57, n.3, p. 21-24, 2005.

ZOMPERO, A.F.; LABURÚ, C.E. As atividades de investigação no Ensino de Ciências na perspectiva da teoria da Aprendizagem Significativa. Revista Electronica de Investigacion en Educacion en Ciencias, v. 5, n. 2, p.12-19, 2010.

WIRZBICKI, S. M. Abordagens e reflexões sobre a significação conceitual de energia em espaços interativos de formação de professores. 141f. Dissertação, (Mestrado em Educação em Ciências), UNIJUÍ, Ijuí, 2010. 